\title{
Un lector beligerante. Las lecturas de Manuel José de Lavardén*
}

\author{
A belligerent reader. \\ The readings of Manuel José de Lavardén
}

\author{
Matías Maggio-Ramírez \\ ORCID iD: http://orcid.org/0000-0002-1106-1381 \\ Universidad Nacional de Tres de Febrero
}

Manuel José de Lavardén, poeta y dramaturgo bonaerense, publicó bajo seudónimo una carta en 1802 en el Semanario de Agricultura, Industria y Comercio de Juan Hipólito Vieytes. Allí cuestionó las lecturas que los eruditos europeos realizaron sobre España y América. El poeta criticó con ahínco los ensayos de ingleses, franceses e italianos que trataron sobre España y América sin nunca haber visitado esos territorios. La epístola de Lavardén evidenció el conocimiento de la cultura impresa europea, su circulación en el Río de la Plata y le sirvió para destacar la civilidad de las costumbres como una estrategia para reforzar la identidad española y americana.

Palabras Claves: Manuel José de Lavardén; Periodismo Colonial; Semanario de Agricultura, Industria y Comercio; Determinismo Climático; Identidad; Civilidad.

Manuel José de Lavardén, a Buenos Aires poet and playwright, published under a pseudonym in 1802 in the Semanario de Agricultura, Industria y Comercio of Juan Hipólito Vieytes. There he questioned the readings that European scholars made about Spain and America. The poet strongly criticized the essays of English, French and Italians who addressed Spain and America without ever having visited those territories. Lavardén's epistle evidenced the knowledge of European printed culture, its circulation in the Rio de la Plata and served to highlight the civility of customs as a strategy to strengthen Spanish and American identity.

Keywords: Manuel José de Lavardén, Colonial Journalism, Semanario de Agricultura, Industria y Comercio, Climate Determinism, Identity, Civility.

Copyright: (C) 2020 CSIC. Este es un artículo de acceso abierto distribuido bajo los términos de la licencia de uso y distribución Creative Commons Reconocimiento 4.0 Internacional (CC BY 4.0).

* El siguiente artículo tuvo una versión anterior, levemente modificado, de la tesis de doctorado «Civilidad imaginada La construcción de la civilidad como signo identitario en la prensa tardocolonial porteña. Un análisis del Telégrafo Mercantil Rural Político Económico e Historiográfico del Río de la Plata y del Semanario de Agricultura Industria y Comercio entre 1801-1803» que fue defendida el 18 de agosto de 2016 en la Facultad de Ciencias Sociales de la Universidad de Buenos Aires. 


\section{Contra la mirada extranjera}

Bajo la gestión del extremeño Francisco Cabello y Mesa —entre 1801 y 1802-, se editó en Buenos Aires el periódico Telégrafo Mercantil, Rural, Político, Económico e Historiográfico del Río de la Plata. En el primer número, se presentó a sus suscriptores la «Oda al Paraná» del poeta y dramaturgo Manuel José de Lavardén. Si bien no volvió a publicar con su nombre en el Telégrafo, sí lo hizo bajo el seudónimo anagramático Fr. Juan Anselmo de Velarde en el Semanario de Agricultura, Industria y Comercio, que circuló en la sede virreinal entre 1802 y 1807 . Allí publicó varias cartas dirigidas a Juan Hipólito Vieytes, editor del periódico, donde defendió el honor americano y español, que fuera puesto en duda en los últimos números del Telégrafo y en la literatura ensayística que se encontró en las bibliotecas porteñas. ${ }^{1}$ En la primera de sus misivas, Lavardén cuestionó al Telégrafo por dar a leer el texto «Política. Circunstancias en que se halla la provincia de Buenos Aires e islas Malvinas y modo de repararse», donde un supuesto viajero sostuvo sin pudor, entre otros dislates, que las porteñas se desvivían por cualquier peninsular, sin importar si llegaban con prontuario a Buenos Aires. ${ }^{2}$ La segunda de sus epístolas, de mayor interés para este trabajo, se publicó en el Semanario de Agricultura de Buenos Aires en 1802 y, un par de años después, en Madrid en El Regañón General. ${ }^{3}$ En esta carta se evidenció la necesidad de rebatir, por parte de la élite letrada hispánica, los argumento falaces contra España y sus territorios americanos que circulaban entre las bibliotecas.

La escritura de Lavardén manifestó en su narrativa una construcción identitaria de múltiples adscripciones. La identidad como un proceso relacional y oposicional tuvo, en este caso, límites marcados respecto a la mirada extranjera. ${ }^{4}$ De esta manera se iluminó la cuestión identitaria como uno de los tantos caminos, que confluyeron en la Revolución de Mayo de 1810. Usualmente se interpretó que el fortalecimiento de la identidad local rioplatense tuvo como disparador las invasiones inglesas de 1806 y 1807, aunque para la élite letrada ya era un tema abordado años antes en la prensa. ${ }^{5}$

1 Un panorama sobre la prensa virreinal porteña se encuentra en Martini, 1998; Pastore y Calvo, 2005; Bonardi, 2006; Maggio Ramírez, 2008; Martínez Gramuglia, 2009; 2010; Navallo, 2010; Maggio-Ramírez, 2015; 2017; 2019a.

2 «Política. Circunstancias en que se halla la provincia de Buenos Aires e islas Malvinas y modo de repararse», Telégrafo Mercantil, Rural, Político, Económico e Historiográfico del Río de la Plata, 5, 2, Buenos Aires, 8 de octubre de 1802, 21. Lavardén, 1802a.

3 Lavardén, 1802b; 1802c. La publicación madrileña es Lavardén, 1804a; 1804b.

4 Hall, 2003.

5 Halperín Donghi, 2002. 


\section{La moda de las introducciones}

«Se ha hecho moda anteponer a las obras una introducción que suele valer más que ellas», escribió Lavardén —antes de tratar los asuntos que le preocupaban — para impugnar la «emulación extranjera» que entre los americanos se adoptó con «demasiada facilidad». ${ }^{6} \mathrm{Su}$ perplejidad se centraba en que los eruditos del Nuevo Mundo apreciaban la lectura de los ensayistas europeos, que desconocían las particularidades del territorio americano y que denigraban a sus habitantes. Lavardén recordó a sus lectores que no se podrían «aplicar sus teorías a la práctica de nuestra nación, [porque] mal podrán sernos útiles los que no nos conocen, o si nos conocen es manifiesto que trata de alucinarnos. Me inclino a lo primero, y me parece preciso desmontar el terreno en que habremos de edificar». ${ }^{7}$

El desconocimiento de los letrados del Viejo Mundo fue comprobado por Lavardén al revisar la dramaturgia española y francesa. Si los propios eruditos europeos ignoraban la geografía e historia de su continente, con más razón podían desconocer el territorio americano. Con una amplia erudición literaria, el poeta del Paraná marcó los yerros que «con intolerable anacronismo y geográfico error» encontró en obras de Pierre Corneille, Pedro Calderón de la Barca y Vicente Antonio García de la Huerta, entre otros. ${ }^{8}$ François Marie Arouet, Voltaire, además de presumido para el parecer de Lavardén, contaba con un profundo desconocimiento sobre lo español, tanto en su geografía como en su historia y costumbres:

Pero lo muy gracioso es, que ignorando Volter [sic] cuando a España concierne, quisiese fachendear afectando la posesión de nuestro idioma. Así es que escribiendo al caballero Teodati le recomienda la variedad de nuestras terminaciones, y armonía de nuestros versos, poniendo por ejemplo este ridículo endecasílabo: los hombres, las historias, las costumbres. Con razón el italiano lo silbó con las mismas SS que amontonó en un verso. ${ }^{9}$

6 Lavardén, 1802b, 81.

7 Ibidem, 82.

8 Lavardén declara en estos términos los errores geográficos e históricos: «El gran Corneille escribiendo la tragedia del Cid, que lo inmortalizó, pusiese la escena en Sevilla, con intolerable anacronismo, y geográfico error. Bien sé que un poeta no es un historiador pero no debe faltar a la verdad histórica, mientras no le obligue a ello el tejido del drama. En este caso no sólo puede, sino que debe trastornar la historia. Por eso tanto pecó Calderón haciendo dar al Tetrarca un diabólico salto desde Jerusalén al mar, faltando a la geografía, como Huerta enviando a cazar al Almirante de Raquel en una situación impropia por seguir servilmente la crónica de D. Alonzo. A Corneille tanto le importaba el Duero como el Guadalquivir; pero aquel era el verdadero lugar de la acción». Idem.

9 Idem. 
Con independencia de los errores tipográficos en los nombres de los protagonistas de la correspondencia entre Voltaire y Deodati de Tovazzi (que versó sobre la excelencia de la lengua italiana y que fue publicada aproximadamente en 1761), se evidenciaba la ignorancia sobre el mundo ibérico por parte de los doctos galos. ${ }^{10}$ Lavardén ya no toleraba en silencio «el desdén con que los extranjeros y los españoles, que hacen gala de remedarlos, tratan de un romance de la invención de [Antonio de] Solís la famosa historia de nuestro Hernán Cortés». ${ }^{11}$ Desde los confines del orbe borbónico se buscaba configurar una narración de la historia en clave americana, donde se aunaran el conocimiento del pasado, las costumbres y el territorio.

La pregunta por el trabajo del historiador - distinto al narrador-en la construcción de un relato verosímil, ocupó el interés de Lavardén en su rastreo de los orígenes de la decadencia americana. Nuestro erudito criollo pasó por alto las críticas de Guillaume Thomas François Raynal, quien argumentó que la descripción de los incas era el producto de la imaginación exaltada de los españoles que minaba la confiabilidad de las fuentes. ${ }^{12}$ El poeta del Paraná objetó el uso de la analogía clásica en el relato histórico porque entraba en oposición con la mirada del testigo y protagonista de la historia. Lavardén coincidía con la necesidad de rechazar «el uso promiscuo de analogías clásicas para estudiar los sistemas de gobierno amerindio precolombino», como era usual en la historiografía española en los siglos XVI y XVII. ${ }^{13}$

Los filósofos de gabinete dieciochescos valoraron la verosimilitud de las obras históricas de los siglos anteriores, pero no pudieron distinguir en ellas la pervivencia de los relatos clásicos. La estructura de las obras en las que abrevaron los pensadores europeos era deudora del estilo narrativo de las ficciones de la Antigüedad. A los personajes históricos se le atribuyeron características de los héroes imaginarios. La narrativa se escurría en las obras históricas. «Bueno es querer comparar la verdadera historia de Cortés a la Ciropedia de Xenofonte. Aventuraré una observación, la sola que puede disculpar tamaño error», escribió el poeta criollo que se situó en la misma tesitura que Williams Robertson. ${ }^{14}$ Lavardén encontró que la

10 La correspondencia aludida por Lavardén se reproduce en Voltaire, 1883 [1761], 166-172.

11 Lavardén, 1802b, 83. La obra referida es Solís, 1684.

12 Cañizares Esguerra, 2007, 76.

13 Lavardén, $1802 b, 84$.

14 Lavardén, 1802b, 83. 
narración centrada en la huida y triunfo de Cortés en México fue articulada en una historia de doce meses, la misma duración que la Eneida de Virgilio. También halló que para Juan de Torquemada los españoles fueron caracterizados como los personajes de la Ilíada, descriptos por Homero. La analogía de la antigüedad clásica era «la causa de que se alucinen algunos eruditos extranjeros que se siguen copiando por nuestros semieruditos galomaníacos» ${ }^{15}$ La utilización de la estructura ficcional en la escritura histórica presuponía que los lectores tenían competencias para comprender las nuevas significaciones que contaminaban el relato histórico. Esta observación sirvió para minar la veracidad de las obras de los filósofos y eruditos europeos del siglo XVIII que abordaban temas americanos. Es decir, tomaron los relatos y memorias históricas como fuentes documentales sin percibir que estaban adulteradas con la estructura y la exacerbada imaginación de la literatura clásica.

La obra Origen, progresos y estado actual de toda la literatura, del jesuita Juan Andrés, tuvo una amplia circulación entre los eruditos locales. ${ }^{16}$ Fue citada por Lavardén en sus epístolas públicas y se encontró entre el elenco fundacional de libros de la Biblioteca Pública de Buenos Aires en $1810 .{ }^{17} \mathrm{El}$ jesuita sostuvo que la imaginación, es decir, la literatura ficcional, los rasgos satíricos, los epigramas y la poesía, no debían inmiscuirse en la solemnidad de la historia. Prueba de esta conjunción es la obra de Voltaire, pues

no puede leerse aquella historia sin que el placer vaya acompañado con el enfado, y sin que con el gusto de la lectura se excite la indignación. Tantas gracias de imaginación y de estilo, como también de ingenio y de erudición empleadas en narraciones por la mayor parte o falsas o alteradas, en impías reflexiones. ${ }^{18}$

La confianza en la narración histórica —en la veracidad del relatose encontraba socabada por la imaginación, por «las frecuentes falsedades esparcidas» y por los «rasgos satíricos y propios de los epigramas en vez de un estilo grave y majestuoso correspondiente a la dignidad de la historia». ${ }^{19}$ La problematización de la historiografía americana, al correr el velo sobre las estrategias narrativas de la escritura de la historia, fue un tema inusual en

15 Lavardén, $1802 b, 84$.

16 Peire, 2008, 109-155.

17 «Primeras donaciones de libros a la Biblioteca Nacional de Buenos Aires», Revista de la Biblioteca Nacional, 10, 30, Buenos Aires, 1944, 493-504.

18 Andrés, 1793, 171.

19 Idem. 
el Semanario de Agricultura. El registro discursivo de una esquela pública buscaba la complicidad de la élite letrada. Se suponía que compartían las lecturas que se mencionaban para así reunir ejemplos contra la crítica europea sobre América. Lavardén supo sembrar dudas sobre la verosimilitud de las obras históricas, que florecían entre los libreros de los eruditos americanos, por ejemplo al cuestionar su estructura narrativa. La historia americana se mezclaba con la ficción, en manos de aquellos letrados europeos que nunca habían cruzado el Atlántico para ser testigos en su narración. La identidad local, en su múltiple adscripción (porteña, americana y española), necesitaba demarcar sus límites aunque fueran porosos. ${ }^{20}$ En este sentido, Lavardén sostuvo que

los extranjeros que tratan de España tienen prurito de denigrarnos por disimular la ignorancia en que están de nuestras cosas. Fingen con descaro para llenar con patrañas el vacío de sus defectuosos conocimientos. Reynal divierte, pero ¿qué jugo podremos sacar de quien dice que en Filipinas como en toda la América el despotismo de los gobernadores no conoce más freno que la dominante autoridad del clero? ${ }^{21}$

\section{La risa por Raynal ${ }^{22}$}

La Histoire philosophique et politique des établissements et du commerce des Européens dans les deux Indes fue leída por el jesuita Juan Andrés con curiosidad, dado el éxito que tuvo su circulación, pero no como una buena historia. ${ }^{23}$ La trama arborescente y desordenada, tal vez fruto de la escritura colaborativa donde participó Denis Diderot, abarcaba desde «disertaciones sobre el color de los negros, cuadros históricos, disertaciones filosóficas y descripciones poéticas ocupan tal vez más de la mitad de aquella historia, y privan al docto lector de muchas noticias de aquellos establecimientos [...]». ${ }^{24} \mathrm{El}$ jesuita español tildó de inútiles las múltiples digresiones del abate Raynal donde brillaba su estilo «florido, brillante, sublime, enérgico y animado», que fue capaz de seducir a una «multitud

20 La problematización de la identidad criolla porteña se puede rastrear en Halperin, 2002; Chiaramonte, 2007; González Bernaldo de Quiroz, 2000.

21 Lavardén, $1802 b, 84$.

22 El siguiente apartado tuvo una versión preliminar en la revista La Biblioteca en el marco de la beca de investigación Ezequiel Martínez Estrada en el fondo documental de la Biblioteca Nacional de la República Argentina Mariano Moreno en 2008. Maggio Ramírez, 2009, 262-284.

23 Silvio Zavala realizó un extenso trabajo de rastreo bibliográfico de las distintas ediciones de Raynal desde 1770 hasta 1821, que fue recuperado en Leal, 1981, 128. Andrés, 1793, 175-178.

24 Idem. 
de lectores vulgares, y aún de deslumbrar a los doctos y sensatos». ${ }^{25} \mathrm{Se}$ lamentaba de que el autor francés no hubiera refrenado las «distracciones de su imaginación» y «los adornos de falsa filosofía y de vana retórica». La primera edición de la obra de Raynal de 1770 fue publicada en Ámsterdam de manera anónima y pronto fue prohibida por el Santo Oficio en París en 1772. A los pocos años se extendió la interdicción a Roma en 1774 y a Madrid en 1779. Los mismos criterios se aplicaron, tiempo después, a la Historia Antigua de México de Francisco Javier Clavijero para bloquear su publicación en España en la casa de Antonio de Sancha. ${ }^{26}$ Se argumentó que se fomentaba el tolerantismo y se injuriaba a España y a los españoles «por las crueldades en América han alejado más católicos de la comunión romana de los que han hecho cristianos en las Indias». ${ }^{27}$

En 1784, apareció en Madrid una adaptación de la obra de Raynal con el título Historia política de los establecimientos ultramarinos de las naciones europeas, firmada por Eduardo Malo de Luque, seudónimo de Pedro Francisco de Suárez de Góngora y Luján, duque de Almodóvar del Río. ${ }^{28}$ Para sortear la censura, suprimió «las expresiones violentas contra la colonización española y podó el texto de todas las manifestaciones antirreligiosas». ${ }^{29}$ Bajo el seudónimo de Francisco María de Silva, el duque publicó Década epistolar sobre el estado de las letras en Francia en 1781, donde sostuvo que «esta célebre obra [la Histoire de Raynal] es la más seductora, la más depravada, la más curiosa y de extensa instrucción, la más inductiva en errores de toda especie, y la más buena y más mala de cuantas se han escrito en estos últimos tiempos». Así pues, consideró que la obra merecía ser purgada para leerse sin sobresaltos, pues la producción ensayística del abbé contaba con «grandes retazos [que] son dignos de consideración. Contiene memorias, noticias y cálculos grandemente sacados. Sería útil que una mano hábil se dedicase a extraer de dicha obra, entre tanto montón de espina y cizaña, el bello trigo que en ella se encuentra». ${ }^{30}$

Raynal, conocido por sus polémicas contra los españoles y su sistema colonial, no se ganó el apoyo de los americanos porque también los cuestionaba por su herencia hispánica. Las élites criollas ilustradas «no ignoraban

25 Idem.

26 Maggio-Ramírez, 2019b.

27 Defourneaux, 1973, 145.

28 El libro de Malo de Luque se registró en el elenco fundacional de la Biblioteca Pública de Buenos Aires en 1810. «Primeras donaciones...», Revista de la Biblioteca Nacional, 1944, 493-504.

29 Leal, 1981.

30 Suárez de Góngora y Luján, 1781, 109-113. Defourneaux, 1973, 201. 
sus ataques contra la decadencia, la indolencia y la incapacidad de los habitantes de la América Meridional (incluyendo los criollos) para gobernarse a sí mismos $[\ldots] »,{ }^{31}$ por lo que se sintieron insultados por un francés que no había cruzado las fronteras de su gabinete. En España, el libro de Raynal fue reseñado en el periódico Espíritu de los mejores Diarios Literarios que se publican en Europa, que se leía con fruición en Buenos Aires. ${ }^{32}$ En la edición del 5 de enero de 1789 se publicó un comentario ante la décima reedición in octavo en diez tomos. Allí se tildaba de revulsiva la historia basada en crónicas de viajes escritas por viajeros sin brújulas en la comodidad de su hogar. En un fragmento del texto periódico se advierte la animadversión contra el abate:

El libro fue condenado a ser lacerado y quemado como impío, sedicioso y dirigido a sublevar los pueblos contra la autoridad soberana, y a trastornar los principios fundamentales del orden civil. Si el señor Raynal deseó la gloria del martirio vió satisfechos sus deseos: hele ya rodeado de los honores de la confiscación de los bienes, única pena que no pudo imponerse a Juan Santiago Rousseau, otro Sócrates anatematizado. ${ }^{33}$

Ya cimentada su fama a mediados del siglo XX, se descubrió que la escritura del abbé era colaborativa, entre otros, en coautoría con Denis Diderot. Tanto en la edición de 1770 como en la de 1774 no se mencionó la firma de Raynal. Desde la tercera edición, de 1780, el abate asumió la paternidad de la obra al incorporar su retrato. Tras este desvelamiento tuvo que exiliarse a la corte de Federico II de Prusia, de donde marchó a la de Catalina II de Rusia, debido a las prohibiciones que padeció su libro en Francia, país al que regresó unos años antes de la Revolución. ${ }^{34}$ La crítica antiimperialista, así como el rechazo a la esclavitud, le granjearon al autor no pocos disgustos al ver su obra «puesta en el Índice, desgarrada y quemada como impía, blasfematoria, con tendencia a sublevar a los pueblos contra la autoridad soberana y a trastornar los principios fundamentales del orden civil». ${ }^{35}$

31 Ette, 2000, 167-191.

32 Peire, 2008, 109-155.

33 «Juicio de la Historia filosófica y política de los establecimientos y del comercio de los europeos en las dos Indias, por Guillermo Tomas Raynal en 10 tomos; sacado de una obra periódica», Espíritu de los mejores Diarios Literarios que se publican en Europa, 162, Madrid, 5 de enero de 1789, 763-766. Cursivas en el original.

34 Pontón, 2011, 7-17.

35 Hazard, 1985, 91. 
La Historia de las dos Indias fue una obra colectiva donde se sumaron las plumas de distintos filósofos que se ampararon en la impunidad que les otorgó Raynal, al figurar como autor del texto y correr con los riesgos del exilio. El abbé reprodujo los textos de sus colaboradores, tanto de forma fragmentaria como completos, recortó los textos y los anudó con los suyos para articular su argumentación. Herbert Dieckmann comprobó en 1950 la hipótesis de que Diderot, con unas setecientas páginas, había sido uno de los colaboradores fantasmas. Se pudo comprender que parte del éxito de la obra se debió a que los textos más incendiarios y radicales eran del editor de la Enciclopedia. De hecho, en el Suplemento al viaje de Bougainville o diálogo entre $A$ y $B$, el mismo Diderot se encargó de despejar sospechas sobre su posible intervención en la obra de Raynal. El texto se publicó en 1796, ya fallecidos tanto Diderot como Raynal, en la Correspondencia Literaria de los hermanos Jacob y Wilhelm Grimm. En el diálogo IV, después glosar la historia de Miss Polly Baker frente a un jurado en los Estados Unidos, se pone en duda la autoría del relato sobre las desventuras de Baker con estas palabras:

B: No sé si el abate Raynal relata el hecho y el discurso en su Historia del Comercio de las dos Indias.

A: Una obra excelente y tan distinta de las que la precedieron que se llegó a pensar que el abate hubiera empleado manos extrañas.

B: Es una injusticia.

A: O una maldad. Se deshoja el laurel que ciñe la cabeza de un gran hombre y se deshoja tan bien que no le queda más que una hoja.

B: Pero el tiempo reúne las hojas dispersas y vuelve a rehacer la corona.

A: Pero el hombre ya ha muerto; ya sufrió la injuria que recibió de sus contemporáneos y es insensible a la reparación que obtiene de la posteridad. ${ }^{36}$

Raynal escribió inspirado en las teorías que postulaban el determinismo climático del conde de Buffon y su transposición, en clave de teoría política, en la obra de Charles Louis de Secondat, barón de Montesquieu. Por tanto, buscó que los lectores tomaran conciencia «del valor económico de las colonias; y por eso tantas cifras mostrando índices de producciones o indicando el estado de la población y las observaciones sobre el clima», que no solo estaba ligado al cultivo sino a la salud y costumbres de los habitantes. ${ }^{37}$ Así pues, desplazó el eje de atención de las riquezas minerales, que llevaron a la ruina a las colonias españolas en la mirada del abbé, para

36 Diderot, 1999 [1796], 100.

37 Leal, 1981. 
centrarlo en la naturaleza poco explotada. No obstante, se le achacó que su obra no tuviera interés en conocer las costumbres y naturaleza de México o Perú, ya que solo se preocupaba por indicar dónde había minas de oro. ${ }^{38}$

Desde la perspectiva hispánica, Lavardén contrastó las palabras de Raynal. El porteño declamó que en España no se había visto el derramamiento de sangre propio de la Inglaterra medieval. El criollo acusaba de ignorancia al abate porque

creería que sucedía en España lo que en Francia, en donde se gobernaban con ignominia de su decoro, por el derecho escrito de los romanos, y por los fueros de las provincias que llamaban droit contumier [...] ha mucho que España tiene leyes fundamentales que jura su Rey en su inauguración. Leyes fundamentales son las que hoy más a la moda se llaman constitucionales. ${ }^{39}$

España se encontraba a la moda, contaba con sus leyes constitucionales y las recriminaciones contra la Iglesia eran nimiedades comparadas con la historia de la institución en Francia. Esta fue la escueta defensa de Lavardén ante la ráfaga crítica de Raynal, recargado con Buffon y Montesquieu. «Reynal divierte», según el poeta, gracias a las incoherencias de su obra que no miró al interior de Europa antes de criticar el continente americano.

\section{Castañas y decadencia económica española}

Tres cosas influyen sin cesar sobre el espíritu de los hombres: el clima, el gobierno y la religión. Es el único modo de explicar el enigma de este mundo.

Ensayo sobre las costumbres

Voltaire $^{40}$

La voracidad literaria de Lavardén parece no haber tenido límites. La élite letrada porteña se mostró ávida de novedades literarias desde los confines del imperio borbónico. Obras en francés, italiano e inglés poblaron las bibliotecas particulares, según se desprende de los relevamientos realizados entre inventarios y testamentos. ${ }^{41}$ Era razón suficiente para comentar una obra en el Semanario, al menos para Lavardén, porque «acaba de salir»

38 Idem.

39 Lavardén, 1802 b, 85.

40 Citado en Hazard, 1985, 219.

41 Parada, 1997; 1998a. Peire, 2008. 
de las imprentas europeas. Más aún si había gozado de traducciones que funcionaban como signo de validación del autor en otros mercados literarios. No pudo contener su apetito erudito y sin pudor escribió que «devoró» el libro aunque le resultó indigesto. En la obra en cuestión «Geografía universal de Mr. Gutrie [...] se da[ba] una noticia sucinta de la historia de las costumbres, del suelo, y producciones de todas las Provincias. ¿Quién mejor podría desempeñar este plan que un inglés?». ${ }^{42}$ En 1800 se había comenzado a publicar los tomos de la traducción francesa y recién en 1804 fue tomada como base de partida para la traducción al castellano. ${ }^{43}$

La intención de Lavardén de estar al día de las discusiones culturales de la metrópolis se demostró no solo en los pocos registros de su biblioteca, donada por su hermana a la Biblioteca Pública de Buenos Aires, sino por los comentarios que hacía de sus lecturas en la prensa virreinal. ${ }^{44}$ Le convenció hincar el diente a los tomos de Guthrie la nacionalidad del autor, ya que los ingleses tienen «una marina igual a la de la Europa entera», «sobresalen en las ciencias naturales» $\mathrm{y}$ «circuyen el orbe» en sus viajes. ${ }^{45} \mathrm{Las}$ razones de su lectura indigesta se originó cuando revisó la entrada dedicada a España. Lavardén se sintió defraudado. Los preconceptos que tenía sobre la erudición inglesa se esfumaron al leer, por ejemplo, que los catalanes

el día primero de noviembre en que celebran la fiesta de todos los santos se juntan a comer castañas, porque creen que cuantas castañas engullan aquel día con fe viva, otras tantas almas sacan del Purgatorio. ¿Se podrá esto creer si no se viera?

42 Lavardén, 1802b, 85

43 En el libro Plano de la villa y corte de Madrid, de Fausto Martínez de la Torre y Josef Asensio, impreso por Joseph Doblado en 1800, se encontró un pliego (con distinta numeración) al terminar el volumen con el Catálogo de los libros que se encontraban a la venta en la librería de Cuesta. En él, se halló el libro Geografía universal descriptiva, histórica, industrial y comercial de las cuatro partes del mundo, escrito en inglés por Guillermo Guthrie y traducido al castellano en 14 tomos en octavo marquilla. Sin embargo, al consultar el catálogo de la Biblioteca Nacional de España, se ha encontrado el registro de que a partir de 1804 se publicó la obra de Guthrie en castellano, es decir, posterior a la aparición del texto firmado por el seudónimo de Lavardén.

44 Martina de Lavardén y Arce, hermana de Manuel y esposa de Pedro de Arce, donó a la Biblioteca Pública de Buenos Aires los libros de su hermano. Según el registro de donaciones, entre otros, se entregaron los siguientes: Condillac, El comercio y el gobierno considerados en relación mutua, en octavo, en francés; Serra, La ciencia del comercio etc., en octavo, en italiano; Pluche, Espectáculo de la naturaleza, 16 tomos, en cuarto; Weuves, Reflexiones históricas y políticas sobre el comercio de Francia con sus colonias de América, en octavo, en francés; Valcarcel, Agricultura general y gobierno de la casa de campo, 7 tomos, en cuarto. Véase la lista completa en «Libro de donaciones», Revista de la Biblioteca Nacional, 11, 32, Buenos Aires, 1944, 501-502. Los libros de Serra y Condillac no se hallan actualmente en la institución. No hay registro de la donación de las obras de Raynal y Guthrie, por lo que se desconocen las ediciones que manejó Lavardén.

45 Lavardén, $1802 \mathrm{~b}, 85$. 
Convenzámonos que ingleses y franceses tienen con nosotros alguna picacena. Apelemos a la erudita Italia. ${ }^{46}$

La obra, Geografía universal descriptiva, histórica, industrial y comercial de las cuatro partes del mundo, publicada en inglés en 1790, criticaba a los españoles después de tomar como válidas la reproducción de las leyendas y narraciones de viajeros como si fueran observaciones verídicas por parte de los eruditos que visitaron España en la comodidad de su biblioteca.

Ante las descripciones poco amables, que leyó de la traducción francesa, Lavardén esgrimió la identidad española para enfrentar la obra del inglés. Un tópico usual y de larga tradición en la literatura inglesa se escurrió en la prosa de Guthrie. Se anudó la religiosidad española con la superstición oscurantista, por lo tanto se alejaba a España y a sus territorios de la racionalidad ilustrada. La veracidad de su relato estaba otorgada tanto por el rol de la armada inglesa en sus viajes, como por las ciencias naturales, especialmente por su sistema de observación y clasificación. Tal creencia se quebró cuando no se aplicó la observación y el análisis de las ciencias naturales, pretendido como objetivas las referencias a las costumbres y prácticas sociales. Lavardén confirmó que ingleses y franceses tenían algún resquemor y resentimiento frente a los españoles.

\section{Contra las causas de Serra}

Si el comercio y el dominio de los mares estaban en manos inglesas, la erudición habría de hallarse en Italia, según Lavardén, por lo que consultó La scienza del commercio: trattato storico-economico-politico de Giovanni Serra, que se publicó en 1793. La obra fue diseccionada con desconfianza para comentarla ante los lectores del Semanario. Serra «no sólo da[ba] reglas generales, sino que se refiere en particular a todos los países industriosos y mercantes» y además enumeró las causas de la decadencia española que se glosó en el periódico:

En este reino (dice el Monseñor) «el comercio, las artes, y la agricultura están en suma decadencia. Las causas a que las atribuyen los políticos de las otras naciones son: Primera, a los minerales de América. Segunda, a la falta de población. Tercera,

46 Lavardén, 1802b, 86. 
a no haber conocido la política de las otras naciones. Cuarta, a una cierta especie de inercia. Quinta, y finalmente al rigor de la antigua Inquisición». ${ }^{47}$

Con renovada fe ante la escritura extranjera, el poeta del Paraná se acercó a Serra, ya que confió en que la «obra es una colección de lo más selecto que en Europa se ha escrito en la materia económica». ${ }^{48}$ Lavardén, a pesar de estar en desacuerdo, indagó las razones que el italiano atribuyó a sus colegas europeos que anunciaron la decadencia española y, por ende, americana. El pretendido repliegue ibérico fue rebatido con la enumeración de productos de exportación, aunque se concedió al monseñor italiano que era imposible de negar el presente si se comparaba con la España del Siglo de Oro. El apogeo de los reinados de Carlos V y Felipe II, gracias a la explotación minera americana, fueron los momentos centrales en la historia española que contradecían la argumentación de Serra. También recordó el poeta que los miles de millones de pesos que partieron de América no han quedado en España, sino que fomentaron el comercio, y se han distribuido entre Francia, Inglaterra, la India y la China ${ }^{49}$ Se podría pensar con Serra, a diferencia de Lavardén, que la decadencia de España se encontró cifrada en la ausencia de un proceso de industrialización. Entre las múltiples causas, se podría mencionar la legislación de la limpieza de oficios, que desalentó las actividades manuales, por lo que se centró la actividad económica en la intermediación en vez de completar la cadena de valor de los productos desde la manufactura y la comercialización.

La falta de población fue la segunda causa de la decadencia hispana según Serra. Lavardén les recordó a sus lectores que «un escritor (no me atrevo a decir un sabio español, porque no se rían los políticos de las demás naciones)», apuntó que «la mayor o menor población son efectos del buen o mal estado de la agricultura. Esto es probar con solidez a la española, que la falta de población no es causa, sino efecto de la decadencia de la agricultura». ${ }^{50} \mathrm{El}$ uso recurrente de las analogías de raíz neoclásica le sirvió para sostener que, una vez mejorada la agricultura, aumentaría la población americana. El editor Juan Hipólito Vieytes, en su «Prospecto» para ganar suscriptores, acordó con esta afirmación. En el primer año de aparición del Semanario se publicó una cartilla de agricultura, a partir del diccionario

47 Lavardén, 1802b, 86.

48 Idem.

49 Idem.

50 Ibidem, 88. 
de abate Rozier, para «extirpar» los saberes tradicionales, de transmisión intergeneracional, que recibían los niños sobre la siembra y la cosecha, para favorecer los métodos racionales europeos.

La tercera razón que Serra esbozó hizo diana en la ignorancia española respecto a las noticias sobre la política de otras naciones. La ironía de Lavardén floreció una vez más: «Son muy atentos estos italianos. Acábelo de decir de una vez. El español es a su entender una especie media entre el hombre y el orangután». ${ }^{51} \mathrm{El}$ español es condiderado como un bárbaro urbanita. El poeta del Paraná cuestionó la buena fe que, al igual que él, tenían «muchas buenas almas de entre mis paisanos» en confiar en el juicio de los políticos de otras naciones. Frente a esto se preguntó:

¿Cómo es que las otras naciones con tan consumada política, con tanta ventaja en artes, en comercio, en ciencias, en población, permiten que los bárbaros españoles se tengan agarrado todo lo bueno en sanidad y riqueza, que se ha descubierto por medio de la brújula? ¿Por qué se contentan ellas con lo mezquino y pestilencial? No es por escrúpulo de conciencia, pues a fe mía que el Asia y el África certifican que no son estos señores muy estrechos de manga. ${ }^{52}$

El argumento de Serra, según Lavardén, era que la minería causaba la decadencia de las artes y la agricultura, por lo que las naciones europeas «no quieren destruir esta verdadera riqueza con la posesión de los minerales», pero aun así querían el oro español. La cuarta causa se engarzó con las clásicas lecturas ligadas al determinismo climático, que estuvieron presentes en las bibliotecas de los eruditos dieciochescos y en la prensa tardocolonial. Las obras que propugnaron estas teorías se encontraron en distintas colecciones criollas y autores como Buffon o Montesquieu fueron citados en los periódicos coloniales de toda la América española, entre ellos el Mercurio Peruano.$^{53}$ No obstante, Lavardén se enervó cuando encontró que

51 Lavardén, $1802 \mathrm{c}, 89$.

52 Idem.

53 En los registros de los inventarios y testamentos se halló la obra de Buffon Historia natural general y particular en las bibliotecas de Juan Baltasar Maziel, Ignacio Flores, José Serrano, Francisco de Ortega, José Moscoso y Pérez, Pedro de Altolaguirre, Manuel Hernández Barruso, Nicolás Videla del Pino e Hipólito Vieytes, que lo criticará a partir de la traducción española de Clavijo y Fajardo (Parada, 1998b, 142). También se encontró La historia natural del hombre de Buffon en la biblioteca del intendente de Ejército y Real Hacienda de Buenos Aires, Manuel Ignacio Fernández. Según Guillermo Furlong (1944), en el inventario de la biblioteca de Santiago de Liniers constaba «La Historia Natural, de Buffon, en 26 tomos en cuarto y pasta». También halló Alejandro Parada (1998b, 144) la obra del barón de Montesquieu en los inventarios testamentarios de Juan Baltasar Maziel, Ignacio Flores, Francisco de Ortega, que también conocían a Buffon, y en la biblioteca de Facundo de Prieto y Pulido, Manuel Azamor y Ramírez, Rodrigo Antonio de Orellana y José de San Martín. 
Serra le atribuía a los españoles, y por ende a los americanos, una especie de inercia en sus costumbres, es decir, los tildaba de flojos, perezosos y descuidados, según los sinónimos que se encuentran en el diccionario de la Real Academia Española de 1734. Serra no abunda en detalles para determinar si la pereza es natural o «procedente de causas físicas, o es accidental que pueda removerse». Lavardén, como sagaz lector, encontró que Giovanni Serra había sido influenciado por los textos del citado Montesquieu, quien a su vez abrevó en las teorías de Georges Louis Leclerc, conde de Buffon:

Yo creo que lo atribuya al clima porque el sabio Motezquieu [sic] observó que la actividad crecía en razón directa de la distancia del Ecuador. En efecto cuando hace calor estamos flojos, y con el frío nos da ganas de correr. Por eso los negros congos serán menos activos que los dinamarqueses. Sin embargo los que expulsaron los Moros, los que conquistaron el Nuevo Mundo, los que sostuvieron a un tiempo glorioso sus guerras contra la Francia e Inglaterra debían tener más actividad que los Lapones. ${ }^{54}$

Según Serra, el punto quinto de la decadencia económica fue la Inquisición, por lo que nuestro autor quedó no menos perplejo ante esta relación y se preguntó en el Semanario: «¿Qué tiene que ver la Inquisición con la agricultura y el comercio? ¿Ha prohibido jamás la Inquisición la entrada, y el trato de todos los hombres en España?» ${ }^{55}$ Abogado y devoto, a deducir principalmente por la abreviatura fr. que antecedía al seudónimo empleado, Lavardén se detuvo en algunos detalles para contrarrestar las afirmaciones acerca de que el Santo Oficio había quemado hombres, cuando en realidad quien ordenaba la «quemazón» era el juez real en cumplimiento con las leyes del reino, «que así lo requiere, por respecto a la pública tranquilidad, presumiendo con razón, o sin ella que más vale ahorcar uno que dar lugar a que se maten a millares, como ha sucedido en otras naciones». ${ }^{56} \mathrm{La}$ manzana podrida es preciso sacrificarla antes de que arruine al resto. Si faltara justificar aún más en la racionalidad dieciochesca de la pedagogía del castigo ejemplar, se comparó a España frente a Inglaterra y Francia, «Henrique Octavo quemó a centenares, y los franceses mucho después que nosotros quemaban todavía a los melancólicos que entraban en la manía de que habían hablado con el diablo. Por último no lo han hecho mal los jacobinos». ${ }^{57}$ La melancolía como enfermedad podía ser tratada a través de un cambio en

54 Lavardén, 1802c, 90.

55 Idem.

56 Idem.

57 Idem. 
la dieta del paciente, como se recomendaba desde el Siglo de Oro español, en lugar de enviarlo a la hoguera. El criollo recordó el pasado de ingleses y franceses, estos últimos por quemar enfermos y por el terror revolucionario, para invalidar sus críticas hacia los españoles.

A pesar de afirmar que las artes, el comercio y la agricultura se encontraban en decadencia en España, Lavardén tuvo que reconocer que «no podemos contar con la ilustración de la sabia Europa para salir del laberinto en que nos vemos metidos». ${ }^{58} \mathrm{Si}$ para tratar de escapar del atraso económico e industrial se consulta la literatura de los eruditos europeos que, según el poeta del Paraná, «no nos dicen más que patrañas, porque ignoran de punta a cabo nuestra historia, nuestra situación, y las causas políticas que pueden haber influido», solo resta que con tesón se pueda «meditar, calcular, errar y enmendar» en la práctica, no obstante que para los eruditos franceses y germanos España y sus colonias sean terreno fecundo para la desidia y la pereza. ${ }^{59}$

\section{El clima y las costumbres}

En 1801 se publicó por entregas en el Telégrafo Mercantil el artículo «Geografía. Lecciones para su uso y conocimiento». Allí se describió el amplio campo de estudios de la disciplina de la que «todos creen saber, y aún los literatos se juzgan capaces para escribir de esta ciencia». ${ }^{60} \mathrm{La}$ base del artículo del Telégrafo fue una reescritura de la introducción de la Encyclopedia Metódica dispuesta por orden de materias a las entradas del tomo sobre "Geografía Moderna". Aquella obra, publicada en Madrid por la imprenta de Sancha en 1792, había sido traducida del francés por Juan Arribas y Sorias y Julián de Velasco. Su punto de partida fue el volumen de la Géographie moderne que se editó diez años antes y que formaba parte de la Encyclopédie méthodique dirigida por Charles-Joseph Panckoucke. El tomo primero de la Encyclopedia, sobre geografía, contó con el discurso preliminar de Nicolas Masson de Morvilliers, autor de la polémica entrada «España», que generó la ira de los eruditos peninsulares. ${ }^{61} \mathrm{El}$ texto de

58 Ibidem, 91.

59 Idem.

60 «Geografía. Lecciones para su uso y conocimiento», Telégrafo Mercantil, 2, Buenos Aires, 5 de agosto de 1801,12 .

61 Masson de Morvilliers, 1792, 79-106. 
Masson de Morvilliers fue reescrito en el Río de la Plata tras la traducción ibérica, pero no se publicó completo ya que Francisco Cabello y Mesa, editor del Telégrafo, fraccionó el citado artículo «Geografía. Lecciones para su uso y conocimiento» en cuatro entregas. En la última, del 16 de agosto de 1801, dejó abierta la continuación cuando quedaban por definir las características de la «geografía antigua, la de media edad, y la moderna».

Tanto en el artículo de la Enciclopedia Metódica como en la reescritura de Cabello y Mesa, se explicaba cómo un verdadero filósofo compararía las diferentes costumbres de las naciones, ya que la geografía «participa de todos los conocimientos humanos». ${ }^{62}$ Esta disciplina no solo se ocupaba de los grandes descubrimientos, gracias al trabajo a «fuerza de pruebas y experiencias», sino que también a la hora de describir una provincia o nación habría de «individualizar su situación, y clima, explicando las causas y efectos de este, y en qué consiste disfrutar de las suaves producciones de la naturaleza, o influir en las costumbres el rigor de un aire casi helado, la dulzura de un cielo benigno, y el calor de un sol que abrasa». ${ }^{63}$

En este sentido, se afirmaba cómo el clima de una nación influía sobre las costumbres de sus habitantes. Desde los tratados medicinales hipocráticos y galénicos hasta las lecturas neoclásicas en las obras de Samuel Tissot, Hipólito Unanue, el conde de Buffon y Montesquieu, se estableció la determinación del clima sobre las costumbres y por ende sobre la civilidad. En el siglo de la Ilustración, estos últimos autores llevaron adelante «una de las más antiguas y persistentes ideas en el pensamiento occidental: la de que el hombre es reflejo del ambiente en el que vive». ${ }^{64}$ Las características físicas de cada raza expresaban la capacidad de adaptación del hombre a los distintos climas que contaban con diferentes rasgos culturales y sociales. La anécdota sobre cómo se inspiró Montesquieu para establecer la relación entre las leyes adecuadas que habrían de reglar las costumbres de los habitantes en determinado clima y el temperamento del territorio es conocida pero vale repetirla, porque puso en evidencia la importancia de la observación, de las ciencias experienciales y de la historia natural en las ciencias sociales. Al examinar la lengua de un carnero a diferentes temperaturas, Montesquieu dedujo que el clima influía sobre el cuerpo. Observó la contracción de la lengua ante el frío, que producía «que los hacecillos nerviosos [que] están menos desplegados, semiocultos en sus fundas [...]

62 Idem.

63 Idem.

64 Urteaga, 1993. 
las sensaciones son menos vivas», por ende «en los países fríos se tendrá poca sensibilidad para los placeres, pero dicha sensibilidad será mayor en los países templados y muy grande en los países cálidos». ${ }^{65}$ Para Buffon, la temperatura fría o cálida, húmeda o seca, no solo marca el color de piel de los hombres sino que también la flora y fauna quedarían teñidas con las características que impriman el clima, como la estatura y la fuerza, y en algunos casos no podrían desarrollarse en cualquier latitud. ${ }^{66}$

Montesquieu sostuvo que las personas son más vigorosas en los climas fríos, lo que tendría también su explicación desde la teoría hipocrática de los humores. En un clima frío, la sangre se mueve más libremente hacia el corazón, por lo que el órgano tendría más fuerza y produciría distintos estados mentales como el sentirse valeroso. De esta forma, Montesquieu «compara las gentes de los países fríos a hombres jóvenes y valientes, y las de los países cálidos a hombres viejos y asustadizos». ${ }^{67} \mathrm{El}$ citado artículo «Política. Circunstancias en que se halla la provincia de Buenos Aires e islas Malvinas y modo de repararse», publicado el 8 de octubre de 1802 en el Telégrafo Mercantil, fue criticado con pasión por Lavardén. Su anónimo escriba sostenía que las jóvenes porteñas estaban entregadas a las pasiones, por lo que se podría conjeturar que tal argumento pudo haberse inspirado en Montesquieu cuando aludió a las pasiones señalando que «del mismo modo que se distinguen los climas según el grado de latitud, [...] según los grados de sensibilidad». ${ }^{68}$

En contra de la mera especulación, Lavardén decidió contraatacar la narrativa del determinismo climático con simples hechos reivindicatorios de la historia española. La expulsión morisca, la conquista de América y las guerras con Francia e Inglaterra son hitos que Lavardén enarboló en clave patriótica para desacreditar las teorías de Montesquieu. Demostró que si las elucubraciones del francés fueran correctas, ninguno de los hechos enunciados podrían haberse desarrollado. Los escritos de Lavardén estaban anclados en una comunidad de lectores en el extremo sur del imperio español, por lo que rara vez tuvieron eco en la República de las Letras peninsular. Sin embargo, en este caso, tuvieron una circulación inesperada para los eruditos locales más allá del Atlántico.

65 Montesquieu, 1993 [1748], 64.

66 Urteaga, 1993.

67 Glacken, 1996, 524.

68 Montesquieu, 1993 [1748], 164. 


\section{Diderot y el espíritu nacional}

Las críticas de Lavardén a Raynal se concentraron en los textos que pertenecieron a la pluma de Denis Diderot. La reciente recopilación y traducción de los aportes de Diderot a Raynal permitió leer los cuestionamientos que tuvo la Histoire philosophique et politique des établissemens \& du commerce des européens dans les deux Indes (Ginebra, 1780) por parte de los ilustrados americanos desde otra perspectiva. Para Diderot, «el espíritu nacional es el resultado de un gran número de causas, algunas de las cuales son constantes y las otras, variables» ${ }^{69}$ Las primeras se encontraban determinadas por la situación geográfica, tal como lo sostenían autores como Montesquieu, mientras que las segundas «están consignadas en sus anales y se manifiestan en los efectos que han producido». ${ }^{70}$ En la tensión entre lo dado y la creación, entre lo fijo y lo móvil, se imaginó la nación. Una vez puestas en concordancia las dos causas, se avanzaría hacia el esplendor, la opulencia y la felicidad sin que la búsqueda de la riqueza personal llevara a la ruina pública. La civilidad fue sinónimo de una mascarada ficcional, en tanto gesto aprendido pero para nada apropiado como una segunda naturaleza. La civilidad, en oposición a las buenas costumbres, y como signo de la puesta en escena fue criticada por Diderot cuando escribió sobre la importancia de las ciudades capitales como sede del espíritu nacional:

Las metrópolis de los imperios son el hogar del espíritu nacional, es decir, los lugares donde este se muestra con más energía en el discurso, y donde es más desdeñado en las acciones, salvo en algunas circunstancias, en las que se trata de una cuestión de bienestar general. A medida que la distancia respecto a la capital crece, esta máscara se va despegando, hasta que se cae en la frontera. De un hemisferio a otro, ¿qué queda de ella? Nada. ${ }^{71}$

La tensión entre el centro y la periferia fue en Diderot una crítica feroz al colonialismo extractivo europeo con sed de oro. El erudito francés sostuvo que habría que haber enviado hombres europeos para que se casaran con las mujeres de la región colonizada, porque «la consanguinidad, que es el vínculo más veloz y más fuerte que existe, habría convertido enseguida a los extranjeros y a los nativos del país en una única familia». ${ }^{72} \mathrm{La}$ paz habría

69 Diderot, 2011 [1780], 117.

70 Idem.

71 Ibidem, 118.

72 Idem. 
reinado al haber existido este vínculo, que habría permitido al «bárbaro» aprender las artes. A diferencia del «tono imperioso y arrogante de los amos y usurpadores», que los recién llegados al Nuevo Continente emplearon con sus habitantes, el mestizaje cultural sería útil para entender los conocimientos que le servirían para operar sobre su mundo y mejorar su situación. Encabalgado en la leyenda negra española, Diderot se preguntaba si era posible gobernar desde la metrópolis a través de los mares, pero principalmente cuestionaba la conquista americana mediante una pregunta:

\begin{abstract}
¿Acaso los primeros enviados a quienes se encargó la inspección de aquellas regiones y a quienes se concedió la autoridad para gobernarlas tenían, podrían tener, las luces y las virtudes adecuadas para hacerse querer, para conciliar la confianza y el respeto, para establecer una civilidad, y unas leyes sin sucumbir a la sed de oro que había devastado aquellas tierras? $?^{73}$
\end{abstract}

La contundente respuesta de Diderot sobre la conquista americana no deja dudas: «¡Maldita sea la hora de su descubrimiento!» Lavardén polemizó con los argumentos de Diderot, al igual que otros eruditos, para destacar la América española como un miembro más del concierto de las naciones civilizadas europeas. Los textos que servían de base para denigrar a los americanos eran crónicas del tiempo de la conquista. La verosimilitud y su narración fueron puestos en duda para destacar que la América ilustrada estaba lejos del siglo XV.

\title{
Cierre
}

Para destacar la identidad americana, la primera estrategia que realizó Lavardén fue evidenciar la pervivencia de la narrativa clásica en los relatos de los viajeros al Nuevo Mundo. Demostró así la fragilidad de las fuentes historiográficas que se utilizaron en las historias del siglo XVIII que abordaban tanto la cuestión española como sus dominios americanos.

El segundo eje se centró en rebatir los argumentos de los eruditos europeos sobre la situación económica del imperio español. Lavardén invitaba a leer «nuestra historia [porque] con reflexión podrá darnos luz para salir de tanta oscuridad, y pues es forzoso saber las causas de la dolencia para aplicarla el remedio, tratemos de indagarlas. Este deberá ser asunto de

73 Ibidem, 121. 
otra carta». ${ }^{74}$ Vieytes aprovechó la intervención de Lavardén para reforzar la crítica a Buffón. El francés había sostenido que era necesario fomentar una excursión para capturar vicuñas y llevar varias docenas a Cádiz y de allí a Francia. Se aconsejaba en la memoria de Buffon — quien copiaba al abate Beliardy — que se solicitase a los indios de Montevideo, que andaban entre treinta y cuarenta leguas por día, que fueran a Santa Cruz de la Sierra (en la actual Bolivia) para traer las vicuñas al puerto, donde comenzaría su travesía transatlántica. Vieytes, asombrado por la expedición propuesta por los franceses, coincidía con Lavardén al sentenciar: «convengamos en que el prurito que tienen los extranjeros de hablar de las cosas de España, no conoce límites».

La escritura de Lavardén, bajo el seudónimo anagramático de fray Juan Anselmo de Velarde, no solo circuló en el virreinato del Río de la Plata. Dos cartas se publicaron en el periódico literario español El Regañón general o Tribunal catoniano de literatura, educación y costumbres: papel periódica que se publica en Madrid los miércoles y sábados de cada semana, cuyo primer número salió el primero de junio de 1803 . El «Prospecto» de El Regañón dejaba claro que sería un periódico de crítica, porque tal actividad «purifica las obras literarias, a la manera del crisol que separa la escoria de los metales, reduciéndolos a su verdadera ley y legítimo valor». ${ }^{75}$ La crítica, según se informaba, es sana, útil y agradable, a diferencia de la sátira mordaz y calumniosa que se considera deplorable por el gobierno, que «vela incesantemente para impedir la entrada de este género prohibido». En El Regañón se trataron «todos los ramos de literatura, de artes, de educación y de costumbres, para cuyo efecto se convida a los hombres de talento a que comuniquen al público sus producciones». ${ }^{76}$ En este sentido, las cartas de Lavardén cumplían con el registro de temas que el periódico estaba habilitado a publicar, por lo que la primera se insertó con la siguiente nota introductoria:

Los Números de este periódico que principió en $1^{\circ}$ de Setiembre de 1802 , son muy raros en Madrid. Por este motivo, y por considerar que las siguientes cartas no solo serán leídas con gusto e interés, sino que también se deseará con ansia su continuación, he determinado presentarlas al público. Todo el anhelo del Tribunal no se dirige

74 Lavardén, 1802 c, 91.

75 «Prospecto de un nuevo periódico que se publicará en Madrid [...] El Regañón general o Tribunal catoniano de literatura, educación y costumbres», Gazeta de Madrid, 39, Madrid, 17 de mayo de $1803, \mathrm{~s} / \mathrm{p}$.

76 Idem. 
mas que a hacer apreciable su periódico, reuniendo en él producciones que instruyan y diviertan al mismo tiempo. ${ }^{77}$

No obstante, las cartas se publicaron cambiando la numeración que contaban en el Semanario, lo que implicó que se dejara de lado la misiva en contra del relato de viajes sobre Buenos Aires y Malvinas — publicado originalmente en el Telégrafo- , donde se puso en duda la civilidad porteña. ${ }^{78}$ Por otro lado, tampoco hay registros de que Lavardén o Vieytes supieran del eco transatlántico de esta correspondencia pública. La edición de la prosa de Lavardén en El Regañón general es uno de los pocos casos que demuestra la circulación de la prensa porteña en los ámbitos letrados peninsulares. ${ }^{79}$ Así pues, mientras que en la primera carta el uso del «patriotismo» se ciñó al ámbito local, en la segunda, el criollo americano respondió como español a las «injurias» de los ingleses, franceses e italianos. En esta acción se remarca la identidad como diferencial y móvil frente al Otro que trata de encerrarlo y nominarlo desde la retórica antiespañola.

La voz de Lavardén cuestionó los topoi usuales hasta el estereotipo que se hicieron de la realidad española y en ese gesto comenzó a marcar su diferencia. Se constituyó la identidad por fuera de los relatos externos, pero principalmente habilitó un horizonte de lo decible desde Buenos Aires para contrarrestar la escritura de los viajeros inmóviles y filósofos de gabinete. De esa manera dejó abierto el camino para pensar desde la prensa tardocolonial — bajo la estricta mirada de las autoridades virreinales — la identidad criolla desde su propia lógica sin determinaciones externas. En la pluma de Lavardén, los porteños no tenían costumbres distintas de los europeos. Se cuestionaron los discursos que los cercaban y definían para pronto tomar la palabra.

Recibido, 15 de enero de 2018 Segunda versión, 28 de abril de 2018

Aceptado, 3 de mayo de 2018

77 «Cartas de Fr. Juan Anselmo de Velarde puestas en varios números del papel periódico intitulado: Semanario de Agricultura, Industria y Comercio que se publica en Buenos-Ayres, capital del Virreynato del Río de la Plata en América Meridional», El Regañón general, 56, Madrid, 14 de julio de $1804,445$.

78 Lavardén, 1804a; 1804b. Maggio-Ramirez, 2017.

79 Otro ejemplo son los informes de Manuel Belgrano, Secretario del Real Consulado de Buenos Aires, que se publicaron desde 1795 en el Correo de Mercantil de España y sus Indias, razón por la que se ha insistido en que sea considerado «el primer periodista rioplatense». Díaz, 2005; 2012. 


\section{Referencias bibliográficas}

Andrés, Juan, Origen, progresos y estado actual de toda la literatura, vol. VI, Madrid, Imprenta de Sancha, 1793.

Bonardi, Laurent, «Le Telégrafo mercantil, rural, político-económico e historiográfico del Río de la Plata (1801-1802)», El Argonauta español, 3, en línea 15 de enero de 2006. Disponible en https://doi.org/10.4000/argonauta.1070 [consultado: 25/04/2018].

Cañizares Esguerra, Jorge, Como escribir la historia del Nuevo Mundo. Historiografías, epistemologías e identidades en el mundo del Atlántico del siglo XVIII, México, Fondo de Cultura Económica, 2007.

Chiaramonte, José Carlos, La Ilustración en el Río de la Plata. Cultura eclesiástica y cultura laica durante el Virreinato, Buenos Aires, Sudamericana, 2007.

Defourneaux, Marcelin, Inquisición y censura de libros en la España del siglo XVIII, Madrid, Taurus, 1973.

Díaz, César L., Intelectuales y periodismo: debates públicos en el Río de la Plata 1776-1810, La Plata, Asociación Amigos del Archivo Histórico de la Provincia de Buenos Aires, 2005.

Díaz, César L., Comunicación y revolución, 1759-1810: esfera y espacio público rioplatense: periodismo, censura, prácticas y ámbitos de lectura, La Plata, Ediciones de Periodismo y Comunicación, 2012.

Diderot, Denis, Viaje a Tahití: seguido de Suplemento al viaje de Bougainville o diálogo entre A y B, Palma de Mallorca, José J. de Olañeta, 1999 [1. a ed. 1796], 67-124.

Diderot, Denis, Tratado de la barbarie de los pueblos civilizados, edición y presentación de Gonzalo Pontón, traducción de Palmira Feixas, Barcelona, Pasado \& Presente, 2011 [1. ${ }^{\mathrm{a}}$ ed. 1780].

Ette, Ottmar, «La vuelta al universo en nuestro piso. Lectores y lecturas en la "Histoire des deux Indes"», en Mendoza, Agustín (ed.), Del tiempo y de las ideas. Textos en honor de Gregorio Weinberg, Buenos Aires, s. e., 2000, 167-191.

Furlong, Guillermo, Bibliotecas argentinas durante la dominación hispánica, Buenos Aires, Huarpes, 1944.

Glacken, Clarence J., Huellas en la playa de Rodas. Naturaleza y cultura en el pensamiento occidental desde la Antigüedad hasta finales del siglo XVIII, Barcelona, Del Serbal, 1996.

González Bernaldo de Quiroz, Pilar, Civilidad y política en los orígenes de la Nación Argentina. Las sociabilidades en Buenos Aires, 1829-1862, Buenos Aires, Fondo de Cultura Económica, 2000.

Hall, Stuart, «Introducción: ¿quién necesita identidad?», en Gay, Paul Du y Hall, Stuart (eds.), Cuestiones de identidad cultural, Buenos Aires, Amorrortu Editores, 2003, 13-39. 
Halperin Donghi, Tulio, Revolución y guerra: formación de una elite dirigente en la Argentina criolla, Buenos Aires, Siglo XXI Editores Argentina, 2002.

Hazard, Paul, El pensamiento europeo en el siglo XVIII, Madrid, Alianza, 1985.

Lavardén, Manuel José de [Fr. Juan Anselmo de Velarde, seud.], «Cartas. De Fr. Juan Anselmo de Velarde al redactor del Semanario de Buenos Ayres. Carta I», Semanario de Agricultura, Industria y Comercio, 1, 6, Buenos Aires, 27 de octubre de 1802a, 41-48. Edición facsimilar de la Junta de Historia y Numismática Americana, Buenos Aires, 1928.

Lavardén, Manuel José de [Fr. Juan Anselmo de Velarde, seud.], «Carta 2. De Fr. Juan Anselmo de Velarde, sobre las erradas prevenciones de los Extrangeros en orden a nuestra situación económica» [primera parte], Semanario de Agricultura, Industria y Comercio, 1, 11, Buenos Aires, 1 de diciembre de 1802b, 81-88. Edición facsimilar de la Junta de Historia y Numismática Americana, Buenos Aires, 1928.

Lavardén, Manuel José de [Fr. Juan Anselmo de Velarde, seud.], «Carta 2. De Fr. Juan Anselmo de Velarde, sobre las erradas prevenciones de los Extrangeros en orden a nuestra situación económica» [segunda parte], Semanario de Agricultura, Industria y Comercio, 1, 11, Buenos Aires, 8 de diciembre de 1802c, 89-91. Edición facsimilar de la Junta de Historia y Numismática Americana, Buenos Aires, 1928.

Lavardén, Manuel José de [Fr. Juan Anselmo de Velarde, seud.], «Cartas de Fr. Juan Anselmo de Velarde puestas en varios números del papel periódico intitulado: Semanario de Agricultura, Industria y Comercio que se publica en Buenos-Ayres, capital del vireynato del Río de la Plata en la América Meridional.

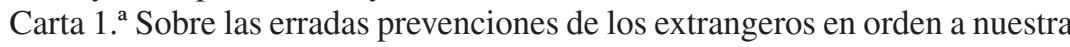
situación económica», El Regañón general o tribunal catoniano: de literatura, educación y costumbres, 1, 56, Madrid, 14 de julio de 1804a, 445-448.

Lavardén, Manuel José de [Fr. Juan Anselmo de Velarde, seud.], «Carta Segunda de Fr. Juan Anselmo de Velarde», El Regañón general, 1, 63, Madrid, 8 de agosto de 1804b, 502-506.

Leal, Ildefonso, «Un fragmento del libro prohibido de Raynal: "Historia de las Indias"», Revista de Historia de América, 92, México, 1981, 127-194.

Maggio-Ramírez, Matías, «Un puro vegetar. Representaciones de la lectura en el Semanario de Agricultura, Industria y Comercio (1802-1806)», en Brunetti, Paulina; Maggio-Ramírez, Matías y Grillo, María del Carmen (eds.), Ensayos sobre la prensa: Primer Concurso de Investigación en Periódicos Argentinos en Homenaje al Prof. Jorge B. Rivera, Ciudad Autónoma de Buenos Aires, Biblioteca Nacional, 2008, 205-292.

Maggio-Ramírez, Matías, «Civilización imaginada. Lecturas sobre civilidad e identidad en el Buenos Aires colonial a través de su prensa periódica», $L a$ biblioteca, 8, Buenos Aires, 2009, 262-285. 
Maggio-Ramírez, Matías, «El color de la palabra. Sobre la sátira de Manuel José de Lavardén y su polémica en el Telégrafo Mercantil (1786-1801)», Dieciocho: Hispanic Enlightenment, 38, 2, Virginia, 2015, 219-238.

Maggio-Ramírez, Matías, «El Telégrafo Mercantil y el fomento de la civilidad. El nacimiento de la prensa de costumbres en el Buenos Aires virreinal», Historia y Comunicación Social, 22, 1, Madrid, 2017, 31-44. Disponible en https:// doi.org/10.5209/HICS.55898 [consultado: 25/04/2018].

Maggio-Ramírez, Matías, «Un polemista sin contrincantes. La prosa americanista del poeta y dramaturgo Manuel José de Lavardén en el Semanario de Agricultura, Industria y Comercio», Boletín Americanista, 78, Barcelona, 2019a, 155-174.

Maggio-Ramírez, Matías, «Civilidad a la mexicana. Lecturas de la Historia Antigua de México de Francisco Clavijero en la prensa virreinal de Buenos Aires (1801)», Nueva Revista de Filología Hispánica (NRFH), 67, 1, México, 2019b, 105-130. Disponible en https://doi.org/10.24201/nrfh.v67i1.3466 [consultado: 25/04/2018].

Martínez Gramuglia, Pablo, «El pensamiento agrario ilustrado en el Río de la Plata: un estudio del Semanario de Agricultura, Industria y Comercio (1802-1807)», Mundo agrario, 9, 18, La Plata, 2009 s/p. Disponible en https://www.mundo agrario.unlp.edu.ar/article/view/v09n18a03/833 [consultado: 25/04/2018].

Martínez Gramuglia, Pablo, «A la búsqueda de lectores: El Telégrafo Mercantil», Question, 27, 1, La Plata, 2010, s/p. Disponible en http://perio.unlp.edu.ar/ ojs/index.php/question/article/view/1000 [consultado: 25/04/2018].

Martini, Mónica Patricia, Francisco Antonio Cabello y Mesa: un publicista ilustrado de dos mundos (1786-1824), Buenos Aires, Instituto de Investigaciones sobre Identidad Cultural, Universidad del Salvador, 1998.

Masson de Morvilliers, Nicolas, «España», Encyclopedia metódica dispuesta por orden de materias. Geografía moderna, vol. II, traducción de Juan Arribas y Soria y Julián de Velasco, Madrid, Imprenta de Sancha, 1792, 79-106.

Montesquieu, Charles Louis de Secondat, Del espíritu de las leyes, Barcelona, Ediciones Altaya, 1993 [1. ${ }^{\text {e }}$ ed. 1748].

Navallo, Tatiana, «Ideas ilustradas: de los manuscritos al Proyecto Geográfico en el Telégrafo Mercantil (18011802)», Tinkuy: Boletín de investigación y debate, 14, Montreal, 2010, 159-197.

Parada, Alejandro E., «Libros de medicina en bibliotecas particulares argentinas durante el período hispánico (Primera parte)», Saber y Tiempo, 1, 4, Buenos Aires, 1997, 463-488.

Parada, Alejandro E., «Libros de medicina durante el período hispánico (Segunda parte)», Saber y Tiempo, 2, 5, Buenos Aires, 1998a, 113-134.

Parada, Alejandro E., El mundo del libro y de la lectura durante la época de Rivadavia: una aproximación a través de los avisos de La Gaceta mercantil 
(1823-1828), Universidad de Buenos Aires, Facultad de Filosofía y Letras, Instituto de Investigaciones Bibliotecológicas, 1998b.

Pastore, Rodolfo y Calvo, Nancy, «Ilustración y economía en el primer periódico impreso del Virreinato del Río de la Plata: el "Telégrafo Mercantil" (18011802)», Bulletin hispanique, 107, 2, Burdeos, 2005, 433-462.

Peire, Jaime, «Leer la Revolución de Mayo: Bibliotecas tardocoloniales en el Río de la Plata», Eadem Utraque Europa. Revista de historia cultural e intelectual, 6, Buenos Aires, 2008, 109-155.

Pontón, Gonzalo, «Presentación», en Diderot, Denis, Tratado de la barbarie de los pueblos civilizados, Barcelona, Pasado \& Presente, 2011, 7-17.

Solís, Antonio de, Historia de la conquista de México: población y progresos de la América Septentrional, conocida por el nombre de Nueva España, Madrid, Imprenta de Bernardo de Villa-Diego, 1684.

Suárez de Góngora y Luján, Pedro Francisco de [Francisco María de Silva, seud.], Década epistolar sobre el estado de las letras en Francia, Madrid, Antonio de Sancha, 1781.

Urteaga, Luis, «La teoría de los climas y los orígenes del ambientalismo», Geo crítica. Cuadernos críticos de geografía humana, 99, Barcelona, 1993. Disponible en http://www.ub.edu/geocrit/geo99.htm [consultado: 25/04/2018].

Voltaire, François-Marie Arouet, «Lettre 4432 à M. Deodati de Tovazzi, Au château de Ferney, en Bourgogne, 24 janvier», en Euvres complètes de Voltaire. Correspondance, 41, edición de Louis Moland, París, Garnier, 1883 [1761], 166-172. 